\title{
Discursos ofrecidos durante el acto nacional de homenaje al Libertador y Héroe Nacional 30 de setiembre de 2014
}

\section{El camino costarricense que Mora iluminó}

Luis Guillermo Solís, Presidente de la República de Costa Rica

Recordamos la muerte pero celebramos la vida de Juan Rafael Mora.

Su muerte fue aviesa y cobarde, constituye un baldón en la historia patria, oscureció por siempre una historia prístina y llena de realizaciones.

Su asesinato refleja lo peor de los antivalores morales porque se ejecutó de la peor manera posible tras un juicio sumario e impío, porque era innecesario y se hizo con saña contra un hombre que había dado lo mejor de sí para salvar a la república.

Recordar la muerte de Mora no es baladí, no es inútil. Hay que recordarla para que nunca más se cometan semejantes atrocidades. Hay que hacerlo pidiéndole perdón, para rescatar la obra extraordinaria y egregia de nuestro Libertador y Héroe Nacional.

Sin embargo, más grande que su muerte es la vida de Mora. Más importante que su muerte es su obra. Debemos dar gracias por su vida y su obra.

Gracias, Juan Rafael Mora, por enseñarnos el valor de la libertad, la cual no tiene precio para un pueblo que se honra en quererse a sí mismo.

Gracias, Juan Rafael Mora, por enseñarnos a vivir con los ojos hacia el futuro, enhiestos, de cara al sol, mirando de frente a los desafíos que la vida nos depara.

Gracias, Juan Rafael Mora, por enseñarnos con tu vida que hay momentos en los que la guerra, la guerra contra la injusticia y la opresión, es el único camino hacia la libertad y el bien.

Este es el Juan Rafael Mora que celebramos hoy.

Agradezco este homenaje hermoso y sencillo como el alma costarricense, profundamente significativo para honrar a nuestro Libertador. Agradezco a las autoridades y a los descendientes de don Juan Rafael que nos permiten recuperar, para recordarlo siempre, el aporte de Mora y sus compañeros que lucharon por la paz y la libertad de Centroamérica. 
La gesta de Mora es de Centroamérica. La gesta de Mora es de la América toda. Si no entendemos la dimensión trascendente de la lucha que libraron nuestros heroicos soldados en Santa Rosa, Sardinal, Rivas y la vía del tránsito; si no recordamos que las banderas de Centroamérica cobijaron esa gesta de 1856 y 57, perdemos una parte de la historia que engrandece a Costa Rica.

Al recordar su liderato que trascendió las fronteras nacionales, que fue capaz de concitar en todo el continente los apoyos que hasta entonces solo Simón Bolívar había logrado, Juan Rafael Mora se convierte en una figura enorme, egregia, gigante en la historia de nuestra América.

Saludo a los héroes centroamericanos que pelearon en esa guerra al lado de Mora.

Nuestros campesinos y sus familias tuvieron que pagar y llevar sobre sus hombros no solo la carga de la guerra y la sangre derramada en las batallas sino también la muerte que produjo el cólera que trajeron los soldados desde Nicaragua.

El pueblo de Costa Rica pagó con honor el atrevimiento de ponerle fin al destino manifiesto en Centroamérica. Lo hizo acompañado de otros pueblos valientes que contribuyeron con su cuota de sacrificio y a quienes hoy recuerdo con gratitud pues merecen honor de los hijos de Juan Rafael Mora.

Aquellos fueron días llenos de espanto y llenos de zozobra, como no se han vuelto a repetir. Fueron excepcionales en la vida temprana de la república los desafíos enfrentados por la generación de Juan Rafael Mora.

Su gesta es tanto más grande porque con audacia, serenidad y temple supieron repeler la amenaza externa, sostener a la patria en el momento más difícil.

No hubo allí duda, no hubo allí miedo, no hubo allí incertidumbre sobre lo que tenía que hacerse. "Ha llegado el momento que os anuncié", dijo Mora. Y el pueblo marchó con él porque había claridad sobre el desafío que Costa Rica y Centroamérica tenían ante sí.

Hoy los desafíos son de otra naturaleza. Afortunadamente no tenemos que derramar sangre de hermanos para defendernos de una agresión externa. Ni hay razón tampoco para que se repitan los actos nefastos que pusieron fin a la vida de Mora.

Pero, al igual que entonces, hoy tiene que haber templanza y tranquilidad, sobre todo lucidez para seguir construyendo la patria que nos legaron Mora y sus valientes. Esta patria reclama educación y salud de buena calidad. Esta patria reclama infraestructura, democracia, ambiente limpio para todos. No entender que la patria requiere de condiciones para crecer, para que haya menos pobres y más alegría en los barrios de nuestras ciudades, es traicionar el legado de Mora. No entender que la frugalidad, la austeridad, la responsabilidad en el gasto, un gobierno que haga cosas y un Estado que las acompañe, es traicionar el legado maravilloso de Mora que nos dio una patria libre que quiere crecer.

Por eso le pido al Libertador y Héroe Nacional, le solicito a Juanito Mora que nos dé en la hora actual -mucho más luminosa que la suya- sabiduría para hacer que esta patria sea merecedora del sacrificio que él y sus héroes nos legaron.

Agradezco a los poderes de la república que han sabido acompañar con serenidad y con visión el camino que Mora iluminó.

Quieran esos caminos llevarnos a la Costa Rica próspera y justa que nuestros padres y nuestras madres avizoraron.

Y quiera el ejemplo de Juan Rafael Mora, una y otra vez, acompañar al tricolor nacional cada día que se enarbole bajo el cielo de Costa Rica.

Una sola es Costa Rica, la eterna, la grande, capaz de mirar más allá de su circunstancia inmediata, convocando como lo hizo Juan Rafael Mora a la libertad, a la valentía, al honor y a la gloria con la voz fuerte que él mismo nos legó. 


\section{La audacia de Juan Rafael Mora, estadista de talla mundial}

Henry Mora Jiménez, Presidente de la Asamblea Legislativa, Costa Rica

La Asamblea Legislativa no solamente rinde un tributo al Libertador y Héroe Nacional sino que continúa con la tarea de saldar la deuda que todas y todos hemos tenido durante tantos años con don Juanito, como sus familiares y amigos más cercanos le llamaban.

Me pregunto si habremos aprendido lo suficiente los costarricenses de hoy del gesto extraordinario y del logro épico por el cual fundamentalmente recordamos a Juan Rafael Mora: obviamente el ser capitán general y el conducir al Ejército patriótico a ganar las batallas de Santa Rosa, Sardinal, Rivas y La Trinidad. Pero no solamente fue una victoria contra una banda de bucaneros y filibusteros.

El triunfo de Costa Rica, de su Ejército y de don Juanito fue una victoria sobre el destino manifiesto, que todavía por entonces se pregonaba desde la Unión del Norte. Fue una victoria que permitió desafiar, como pocas veces en la naciente Hispanoamérica, la doctrina Monroe.

Fue el bautismo del latinoamericanismo. Ciertamente, Hispanoamérica nace con las guerras de independencia en las primeras tres décadas del siglo XIX. Pero no exageramos si decimos que la gesta de Costa Rica y de Centroamérica en 1856 y 1857, representa el bautismo de nuestra América Latina. Fue, sin duda, un triunfo de dimensiones continentales y de implicaciones globales, porque don Juan Rafael fue un estadista de talla mundial.

Su proclama al Ejército, del $1^{\circ}$ de enero de 1855, dejó escritas estas palabras: «Prefiero los azares de la lucha a una paz indecorosa, comprada con vergonzosas concesiones o el silencio de la pusilanimidad». Eso dijo don Juanito a su Ejército antes de iniciar la Campaña.

Una lección que nunca debemos olvidar los costarricenses, tan grande como la gesta misma, fue el logro de la gran unidad nacional en torno a la Guerra Patria. Pueblo, Presidente, Congreso e Iglesia se unieron en esa ocasión como pocas veces lo hemos visto en Costa Rica. Desde luego, se contó con el ánimo, el valor, la decisión y la sangre de un pueblo.

Si bien la naciente oligarquía cafetalera se dividió - una parte optó por un pacto de no agresión con los filibusteros, otra parte pretendía una guerra defensiva-, don Juanito entendió perfectamente a qué nos enfrentábamos. El expansionismo esclavista no pretendía marcar fronteras. Era no solamente deshonroso sino, además, una traición al resto de Centroamérica, vender a Nicaragua a cambio de una supuesta paz para Costa Rica, que nunca llegaría.

Don Juanito también evidenció como pocos el ser un hombre que se adelantó a su época. Mientras filibusteros y esclavistas defendían el derecho a la conquista, que -al igual que hoy- se presentaban como defensores de la ampliación de las fronteras de la libertad, Mora -cercano al pensamiento bolivariano- entendió que no solamente luchaba por el derecho a nuestra existencia, a nuestra soberanía y a nuestra libertad.

También se adelantó a su época y proclamó el derecho a la diversidad cultural. Y, junto a Martí, la importancia decisiva del equilibrio del mundo, perfectamente entendida por don Juanito a mediados del siglo XIX.

Siempre he valorado de los grandes líderes dos atributos especiales: sabiduría y humildad. Profundizando en la vida y en la obra de don Juan Rafael Mora debo agregar un atributo que hizo posible la conducción de la gesta heroica que él adelantó. Me refiero a la audacia. 
La audacia que nos permitió proclamar la república en 1848. La audacia que nos dio aquellas heroicas victorias en Santa Rosa, Sardinal, Rivas y La Trinidad en 1856. La audacia que propició las reformas educativas de 1869 y 1886. La audacia que nos movió a intentar establecer el primer régimen de tributación directa en 1914, en medio de la Primera Guerra Mundial. La audacia que hizo posible la primera legislación laboral y la seguridad social en 1943, en medio de la Segunda Guerra Mundial. La audacia que nos Ilevó a nacionalizar la banca y a abolir el Ejército en 1948.

Extrañamos hoy esa audacia de nuestros próceres, posiblemente cuando más la necesitamos. Audacia para convivir en armonía con la naturaleza. Audacia para abatir la pobreza. Audacia para combatir las discriminaciones de todo tipo. Audacia para revertir las crecientes desigualdades, para desterrar la corrupción, para revolucionar el sistema de transporte público.

¿Será acaso -me pregunto con el deseo de que la respuesta a esta pregunta sea negativa-, será acaso que hoy nos vamos a amilanar y a rasgarnos las vestiduras porque una calificadora de riesgo nos llama a cuentas? ¿Vamos a encorvar nuestros hombros porque esa calificadora nos pide que pretendamos, a hachazos y a escopetazos, acabar con las termitas y los roedores que carcomen la Hacienda Pública?

Antes de concluir, quiero hacer una breve digresión. A los costarricenses nos pasa con el término filibusterismo, lo que posiblemente a los mexicanos con el término malinchismo. Lo usamos a menudo para descalificar a nuestros adversarios políticos. ¿Acaso hemos perdido la capacidad para discernir las nuevas formas de expansionismo, de colonización y de pusilanimidad que no nos dejan ver cuál es realmente la esencia del filibusterismo? ¿Acaso no fue al mismo Juan Rafael Mora a quien el régimen que lo derrocó el 14 de agosto de 1859 y lo asesinó en Puntarenas el 30 de setiembre de 1860, lo llamó "filibustero de la peor ley"?

Quiero terminar con estas sabias y siempre actuales palabras pronunciadas por el maestro Joaquín García Monge el 15 de setiembre de 1921, al pie del Monumento Nacional: "La libertad hay que conquistarla y reconquistarla continuamente. Solo se pierden los pueblos que se cansan de ser libres. Si importa saber cómo fuimos libres, importa más saber cómo conservarnos libres, cómo mantener en asta firme la enseña de los libertadores. El problema que ellos resolvieron en el 56 sigue siendo nuestro problema". Estas palabras de García Monge por la libertad podemos pronunciarlas perfectamente para la democracia, para la independencia, para la armonía y convivencia de todas y todos los costarricenses. 


\section{Juan Rafael Mora: el Héroe que soñó con la Integración Centroamericana}

Sonia Marta Mora Escalante, Ministra de Educación Pública de Costa Rica

Muchas veces hemos escuchado decir que las y los costarricenses no luchamos por nuestra independencia, que nos llegó en el lomo de un caballo mientras las grandes mayorías aún ignoraban que habíamos conseguido separarnos de España, y comenzábamos una vida nueva como nación soberana.

Quizás quienes defienden esta teoría se basan en que no hubo una cruenta guerra para romper nuestras cadenas. Es posible que comparen nuestra historia con la de las naciones sudamericanas y sienten que carecemos de la figura de un libertador militar como Simón Bolívar, José de San Martin o Bernardo O’Higgins. Algunos aluden al carácter pacifista de las y los ticos al igual que a nuestra distante posición geográfica con respecto a los núcleos de poder.

Es cierto que somos un pueblo amante de la paz, pero la historia es clara al narrar que este suelo está lleno de héroes, de personajes valientes y patriotas que salieron a defender con sus ideas y con sus vidas esta patria que es madre de todo cuanto amamos.

Hace 200 años, cuando aún ni siquiera éramos un país independiente, nace en San José don Juan Rafael Mora, hijo de don Camilo y doña Ana Benita. Siendo un niño pequeño llega a nuestro país la Carta de Independencia, en ese momento todo era nuevo para ellos y ellas, hombres y mujeres comprometidas con sus conciudadanos hacen empíricos esfuerzos por darle forma a una nación que necesitaba constituir casi todo.

Un primo segundo suyo es nuestro primer Jefe de Estado, Don Juan Mora Fernández, incluso su padre forma parte del Congreso, pero don Juanito no pensó dedicarse a la política; desde muy joven mostró un gran interés y una notable destreza para el comercio. Marcó el sendero de nuestra economía, negoció rutas de exportación, implementó sistemas más modernos de producción, desarrolló caminos y trajo prosperidad a Costa Rica.

No fue él quien buscó el poder sino la patria quien lo llamó a servirle, y don Juanito respondió con todo su sentido humanista de justicia, de honor y de prudencia, un incansable trabajador y un inquebrantable defensor de la libertad y la independencia. Los valores que imprimió a nuestra nacionalidad son los más altos que han permeado en nuestro pueblo, de su mano y la de otros reconocidos estadistas construimos un proyecto país y la idea de patria.

Mora creía en la libertad y el progreso, por tanto fue un gran propulsor de la educación. Asignó impuestos a la producción para comprar libros para los niños necesitados, instala la facultad de Medicina, Ciencias Legales y Políticas en la Universidad de Santo Tomás, declara obligatoria la educación y establece fondos para financiarla. Esta histórica medida fue llevada 11 años más tarde a rango constitucional y es columna vertebral del desarrollo nacional.

Esta misma generación que asistió al parto de nuestra nación entendió perfectamente el valor de lo que estaban recibiendo, lo acuerparon como un tesoro, lo trabajaron como nobles orfebres y llegado el momento, salieron a defenderlo con sus vidas.

Entre las grietas que se iban abriendo en nuestro vecino del norte se coló un codicioso William Walker, representante de espurios intereses imperialistas que pretendían hacer de nuestra Centroamérica un territorio de esclavos al servicio de acaudalados terratenientes sureños. Nuestra libertad, aquella que recién cuidábamos en brazos, se veía 
amenazada por un contingente bien financiado, armado y entrenado que ya había asumido el poder en Nicaragua y se prestaba a avanzar hacia nuestro país.

Visionario como fue, denunció desde un inicio la amenaza que corríamos, y llamó al pueblo para que saliera en defensa de nuestras fronteras, pero también de nuestros hermanos. Se bajó de su cómodo podio y cedió el poder para colocarse al frente de un improvisado ejército de ciudadanos valientes.

La historia de nuestra independencia se escribió con su sangre, con la sangre de esas mismas personas que pocos años antes transportaron la antorcha de la independencia, los que se cubrieron con tierra para labrar el campo, con tinta para plasmar ideas, las mismas que construyeron caminos, que formaron niños y niñas, que escribieron canciones. Las mismas manos que extendimos afectuosamente para presentarnos en el concierto de las naciones, las convertimos en puño para defender la soberanía centroamericana.

Toda nuestra historia está llena de héroes, algunos enfundaron las armas, otros ejercieron distintas y necesarias labores, pero todos hemos colocado un ladrillo en la construcción de Costa Rica. En especial desde las aulas, desde aquí hemos lanzado proclamas tan importantes y resonantes como las de la gesta heroica del 56, desde aquí seguimos defendiendo nuestra libertad y nuestra independencia.

Solo rompiendo las cadenas de la ignorancia, de la pobreza, de la injusticia social podremos ser verdaderamente libres, solo un pueblo que tiene conciencia de su historia, que trabaja por el presente y sueña con un futuro mejor para ellos y para sus hermanos puede ser llamado soberano.

El Consejo Superior de Educación declaró este curso lectivo como "Año Escolar Libertador Juan Mora", de esta manera rendimos tributo a la figura de un gran estadista, de un notable Jefe de Estado, del hombre al frente de las fuerzas armadas en la gesta centroamericana, de un noble humanista y un soñador de la integración de nuestras naciones.

Quizás la página más negra de nuestra historia recuerda el día en que Mora fue asesinado en un crimen de Estado, ejecutado por sus adversarios horas después de haberse rendido en procura del perdón de sus aliados. Este acto innoble es una marca en la historia democrática nacional, con el paso del tiempo la figura de Mora ha adquirido el reconocimiento que la historia le debía, hoy le recordamos como Héroe Nacional, como Libertador, le erigimos estatuas, nombramos plazas y cantones en su nombre.

Uno de los más importantes actos de redención llegó en 1914, cuando la Junta de Educación de San José acuerda transformar en centro educativo el Cuartel Principal, desde donde se ordena el derrocamiento de don Juanito, en su honor deciden llamar a esa escuela: Juan Rafael Mora. Así lo justificó el Presidente Ricardo Jiménez Oreamuno: "La escuela matará al militarismo, y si no el militarismo matará a la escuela. Por eso, señores, de este cuartel hice una escuela". Hoy, desde esas y muchas otras aulas, marchan valientes nuestros estudiantes, prestos para la defensa de Costa Rica. 


\section{Hagamos nuestra la vida del Padre de la Patria}

Armando Vargas Araya,

Presidente, Comisión Nacional del Bicentenario Morista

La madre de todos nosotros que es la entrañable y querida Costa Rica -la patria adorada por quien nuestra vida daríamos- rinde homenaje nacional al más grande de sus hijos, Don Juan Rafael Mora. Con sumo respeto por sus grandes virtudes, a lo largo de 2014 celebramos el bicentenario de su nacimiento. Sonrojados por la vergüenza, recordamos hoy el imperdonable crimen de Estado que tronchó su existencia terrenal hace 154 años.

Nos convocan al pie de su estatua -erigida por la gratitud cívica en esta Plaza de Juan Rafael Mora- los representantes de la nación electos a la Asamblea Legislativa y los concejales de la municipalidad capitalina porque San José fue no solo su cuna sino también la ciudad que él amó y por la que tanto hizo. La adhesión de los poderes Ejecutivo y Judicial, altas autoridades del Estado, cuerpo diplomático y distinguidas personalidades de sectores sociales diversos, así como la presencia espontánea de numerosos ciudadanos, agrega solemnidad a este acto patriótico, difundido por la internet, la prensa, la radio y la televisión.

El Padre de la Patria nació el 8 de febrero de 1814, en el hogar de don Camilo Mora y doña Ana Benita Porras; casó con doña Inés Aguilar Cueto y procrearon siete hijos. Aprendió las primeras letras y números en la Casa de Enseñanza de Santo Tomás, aunque, en rigor, fue un autodidacta. Desde muy joven se dedicó a los negocios de bienes raíces, comercio, transporte marítimo, minería, caña de azúcar, producción y exportación de café. Fue electo Alcalde de San José en 1837, diputado en las Asambleas Constituyentes de 1843 y 1846, vicepresidente del Estado en 1847 y vicepresidente de la República en 1849 (en esa época, el vicepresidente del Poder Ejecutivo era presidente nato del Poder Legislativo).

A los 35 años de edad, sustituyó al dimitente José María Castro Madriz en noviembre de 1849 y al mes siguiente fue electo presidente de la República para completar el medio periodo restante hasta 1853; fue electo nuevamente para el sexenio 1853-1859 y reelecto para el mandato 1859-1865. Resultó derrocado en un golpe de cuartel el 14 de agosto de 1859.

La década de su gestión administrativa fue excepcional. Entre otros logros, desarrolló las vías de comunicación e impulsó el avance material mediante el fomento del cultivo y la comercialización del café; implantó el Himno Nacional; estableció el Banco Nacional de Costa Rica; logró que el Vaticano erigiera la Diócesis de Costa Rica y que España reconociera la Independencia Nacional. Decretó obligatoria la educación en todas las clases de la sociedad y estableció fondos para la instrucción pública. Ratificó el Tratado Cañas-Jerez, que fijó los límites con Nicaragua. En su gobierno se construyeron el Palacio Nacional, la Universidad de Santo Tomás, el Hospital San Juan de Dios, el Teatro Mora y la Fábrica Nacional de Licores; la catedral, afectada por los sismos, fue reconstruida. Cimentó las instituciones jurídicas que sostienen el edificio de la república. Proyectó la nación deseada hacia el porvenir.

En 1856 y 1857, lideró triunfalmente al pueblo en armas contra las pretensiones del expansionismo esclavista impelido desde Estados Unidos. Destacan sus Ilamamientos y proclamas que inculcaron el sentimiento patriótico y cristalizaron la identidad costarricense. La victoria contra la invasión militar de los filibusteros lo elevó al plano de adalid en Hispanoamérica.

El 17 de setiembre de 1860 desembarcó en Puntarenas, luego de un año en el exilio, a la cabeza de una insurrección popular que lo restauraría en la Presidencia de la República. Fracasada la rebelión, se entregó al Gobierno que improvisó un supuesto "consejo de guerra verbal" para ordenar su homicidio a las 3 de la tarde del domingo 30 de setiembre: ¡la página más trágica y más triste de la historia nacional! Además, los patibularios dispusieron más tarde asesinar su carácter con el envilecimiento sistemático de su honor y su reputación. 
El Poder Legislativo le confirió en 1850 el título de Benemérito de la Patria y en 1857 el grado de Capitán General; en 1957 lo declaró Defensor de la Libertad y en 2010 lo proclamó Libertador y Héroe Nacional. Ciertamente, el parlamento ha dirigido desde siempre la restauración del Padre de la Patria al sitial que por sus méritos le corresponde.

En decisión enaltecedora, el Consejo Superior de Educación acordó denominar el curso lectivo 2014 "Año Escolar Libertador Juan Rafael Mora". En los 5000 centros educativos del país ahora se reflexiona y aprende sobre el legado morista. Las nuevas generaciones tendrán comprensión cabal de dónde venimos, quiénes somos y hacia dónde vamos los habitantes de este vergel bello de aromas y flores, que siempre libre, ostentando alegría, de sus hijos es y será la ilusión.

Un filósofo del cogollo costarricense, Roberto Murillo, enseñaba que hay dos formas de culto a los antepasados: podemos evocarlos muertos, para morir con ellos, o recordarlos vivos, prestándoles nuestra existencia para recibir de ellos algo de su esencia. Y un poeta de la costarriqueñidad, Arturo Echeverría, propuso legarle a la ciudadanía el ejemplo viril de Don Juanito: "Que se oiga su nombre en los mercados y las plazas, / que sea maíz en el hogar del pobre / y agua en la calabaza que refresca al labriego en sus faenas de labranza. / Ahora, al pueblo le toca hacer suya la vida de su Héroe".

En nombre de la Comisión Nacional del Bicentenario Morista, creada por la ley núm. 9165 y nombrada por el Consejo de Gobierno, damos las gracias a quienes organizaron y a quienes participan en este Acto Nacional de Homenaje a Don Juan Rafael Mora.

Escuchemos con respeto y demos vida a este llamado suyo, vigente hoy como ayer: "Marchemos siempre unidos, adelante con fe y constancia en el porvenir". 


\section{San José erigirá el mausoleo del Padre de la Patria}

\section{Sandra García Pérez, Alcaldesa}

Metropolitana de San José

En este año 2014 celebramos el bicentenario del nacimiento de don Juan Rafael Mora al pie de su monumento inaugurado en 1929, estatua que mantiene viva la memoria del hijo más ilustre que ha dado a luz nuestro Cantón Central de San José. Este Acto Nacional de Homenaje al Padre de la Patria es, al mismo tiempo, una expresión de gratitud al estadista que decidió transformar la capital de la República de Costa Rica de una aldea colonial en una ciudad republicana.

Don Juanito nació en la casa de sus padres, doscientos metros al sur de esta Plaza de Juan Rafael Mora. Fue a una escuela cerquita de donde nos encontramos, y en estos alrededores transcurrió su infancia. Aquí mismo prosperó desde joven, como honrado hombre de negocios. En las proximidades de la Plaza Mayor, convertida hoy en el Parque Central, labró su carrera política de Alcalde, Diputado Constituyente, Vicepresidente del Estado y Presidente de la República. A una cuadra de este sitio hizo levantar el Palacio Nacional, única sede edificada en toda la historia del país para alojar a los tres poderes de la república. El centro urbano de la antigua Villa Nueva fue el núcleo geográfico donde transcurrió su vida ejemplar.

Y en razón de esa vida ejemplar procederé a contarlos por qué el Concejo Municipal y la Alcaldía de San José reconocemos un pasivo inmenso con el Libertador y Héroe Nacional. De seguido, voy a decirles cómo estamos pensando comenzar a saldar esa deuda histórica.

El Presidente Mora decidió impulsar un cambio cultural europeizante en aquella población de tan solo quince mil habitantes, uniforme y monótona, sin ningún signo del progreso urbano occidental. El cultivo del cafeto, que se extendió en el entorno de San José, dominó el paisaje y la economía. El comercio del grano de oro comenzaba a producir la diversificación de los patrones de consumo. Ese mandatario de elevada visión, consolidó el Estado y la centralización política, propició la creación de infraestructura y de nuevos espacios públicos en la ciudad.

Al inicio de su Gobierno emitió el Reglamento de Policía que después amplió y mejoró. Ahí estableció las bases para un modelo de crecimiento urbano que incluía la administración, el ornato, la salubridad, la seguridad, el mantenimiento, uso y reglamentación del espacio público, las diversiones públicas y privadas, los servicios a los vecinos y hasta la moral pública. Luego agregó el alineamiento y ancho de las calles y altura de los edificios. Ordenó la nivelación de las plazas públicas y su arborización, la creación de paseos para la recreación popular, el mantenimiento y ornato de las viviendas, el aseo de los espacios públicos, la ubicación de los mercados en el centro de la ciudad y de los hospitales, cementerios y mataderos en las afueras del casco urbano. Estableció la primera Policía Municipal con el sistema de serenos para la seguridad en las calles.

El cambio más destacado en la ciudad fue la construcción de los primeros edificios del Estado, con la adopción de una nueva arquitectura y el inicio de una redefinición del uso del suelo urbano. Durante la Administración Mora se construyeron el Palacio Nacional, la Universidad de Santo Tomás, el Teatro Mora, algunos templos, la Fábrica Nacional de Licores, el Hospital San Juan de Dios, el Sagrario, el Cementerio General, como también el Cuartel y la Plaza de la Artillería.

Muy temprano, Don Juanito propuso la construcción de la primera cañería de hierro en San José. Antes, el agua era conducida desde una acequia del río Tiribí hasta los tanques centrales, por un sistema abierto de canales. El agua se contaminaba por el lavado de la ropa, las mieles del café o el aserrín de los aserraderos. 
El Presidente Mora, que había visitado ciudades de Europa, Norteamérica, el Caribe y Sudamérica, introdujo al comienzo de su Gobierno el alumbrado público con lámparas de aceite. En medio de la Guerra Patria, inauguró otro sistema con lámparas de canfín, reverberos traídos de Francia y postes de hierro colado importados de Inglaterra. El alumbrado cubría las intersecciones en nueve calles centrales de sur a norte y de este a oeste. Los serenos se encargaban de encender, apagar y limpiar los faroles.

Aficionado al teatro y a los conciertos, consecuencia de sus recorridos de empresario por el extranjero, hizo construir el Teatro Mora, cuatro cuadras al oeste de la Plaza Mayor. Fue el primer teatro construido en Centroamérica. Él fue un visionario en todas las áreas. Quería promover la diversión y la civilización, de ahí que el Estado subvencionaba a las compañías teatrales. Apoyó a la Universidad de Santo Tomas, que abrió una escuela central con nuevos métodos europeos en la enseñanza elemental y secundaria. Inauguró en San José varias escuelas y el primer centro de educación de párvulos.

El Concejo Municipal y la Alcaldía de San José estamos felices con las celebraciones nacionales del bicentenario del nacimiento de Don Juan Rafael Mora porque fue bajo su liderato político que nuestra población comenzó a dar los primeros pasos hacia la transformación de aldea colonial en ciudad republicana.

Me complace anunciarles que la ciudad de San José empezará a saldar la enorme deuda histórica con el Padre de la Patria, poniendo en marcha el proceso para honrar su memoria con la construcción de un Mausoleo que tenga una Ilama eterna, donde reposen sus restos junto con los de sus generales José María Cañas y José Joaquín Mora. Hace 138 años que el Congreso Nacional dispuso levantar ese Mausoleo el cual, finalmente, la Municipalidad de San José se propone hacer. Ya comienza a elaborarse el anteproyecto y a buscarse la mejor ubicación para un santuario cívico que será un sitio de peregrinación patriótica de la niñez, la juventud, la ciudadanía y los visitantes extranjeros. Invitamos a los poderes del Estado, a la empresa privada y a la sociedad en general a contribuir para la realización de esta magna obra, testimonio para las generaciones futuras de la gratitud costarricense para con su Libertador y Héroe Nacional. 